\title{
Briefly Review of E-Feedback
}

\author{
Min Zhang \\ Foreign Language Department \\ Nanyang Institute of Technology \\ Henan, China \\ E-mail: naomi812@163.com
}

\begin{abstract}
Given the rapid increase in computerized classrooms at universities across the nation and the increasing number of courses which rely on distance learning, the use of the computer in performing peer review is becoming a crucial tool for the teaching of ESL writing. This paper tries to review briefly the research on the electronic peer feedback (Efeedback). Hopefully, it will bring some insights to the current EFL teachers.
\end{abstract}

Keywords-E-Feedback; review

\section{INTRODUCTION}

Writing is a skill composed of many sub skills. Effective writing pedagogy should seriously consider real student involvement, suggests Huot (2002) ${ }^{[1]}$, in the process of response, assessment, evaluation, revision, and grading. In fact, he says that we must "teach students how to assess" themselves, otherwise "we fail to provide them with the authority inherent in assessment, continuing the disjuncture between the competing roles of student and writer" (p. 169). One student might have strengths in a particular area where another does not have, even if the latter is perhaps overall the better writer.

As "an essential mechanism of scientific progress"(Kern, et al., 2003, p. 39) ${ }^{[2]}$, peer feedback (i.e., peer editing, peer evaluation, peer response, peer mentoring, peer tutoring, peer revision, peer critique, peer comment, or peer review) is well known in the academic world. It is frequently used in both first (L1) and second language (L2) writing classrooms. It is a very necessary skill for quality writing and academic success in general, during which students have to be able to critically evaluate writing and then provide effective feedback. Even if a peer reader makes questionable suggestions or corrections, the writer is forced to either: "(a) defend her writing, (b) look at her writing more critically from a different perspective, (c) seek further clarification or feedback if he/she is not sure" (Rollinson, 2005, p. 30) ${ }^{[3]}$. We all know that it is often easier to be critical than to be creative. By giving students practice in becoming critical readers, we are at the same time helping them towards becoming more self-reliant writers, who are both self-critical and who have the skills to self-edit and revise their writing. As Rollinson (2005) ${ }^{[3]}$ points out, learning to effectively review others' writing may ultimately lead to the creation of better self-reviewers, or students who are able to look at their own papers and accurately assess areas in which they need to improve and revise them. This may in the end be a more achievable pedagogical objective than getting them to do it right first time.

The beneficial effects of peer comments have been emphasized by a number of researchers in L2 writing. Recent researches have found that peer review helped both college (DeGuerrero \& Villamil, 1994 ${ }^{[4]}$; Villamil \& de Guerrero, $1996^{[5]}$ ) and secondary (Tsui \& Ng, 2000) ${ }^{[6]}$ students obtain more insight into their writing and revision processes, foster a sense of ownership of the text (Tsui \& Ng, 2000) ${ }^{[6]}$, generate more positive attitudes toward writing $\left(\right.$ Min, 2005) ${ }^{[7]}$, enhance audience awareness (Mittan, 1989 ${ }^{[8]}$; Tsui \& $\mathrm{Ng}, 2000^{[6]}$ ), and facilitate their second language acquisition (Byrd, 1994 ${ }^{[9]}$; Lockhart \& Ng, 1995 ${ }^{[10]}$ ) and oral fluency development (Mangelsdorf, 1989 $9^{[1]}$ ). However, the current Chinese EFL learners are still, to a great extent, relying on the teacher feedback, which is often ambiguous and ineffective as a result of the present situation of largesize class, tight teaching schedule, and heavy workload. Nevertheless, peer feedback, a complement of the teacher feedback, is seldom used in Chinese English class.

Although most peer response has been done by means of oral or written feedback, a new form of feedback - electronic feedback (e-feedback) has been attracting the current researchers and teachers attention since the Internet offers new ways of interaction and information distribution. Efeedback refers to feedback in digital, written form and transmitted via the web; it refers to both asynchronous communication such as e-mail and virtual synchronous conversation in multi-user domains object-oriented. To explore the effect of e-feedback, a growing body of research has compared traditional face-to-face peer response groups versus computer-mediated peer conferences in the context of university or pre-college writing classes. A number of such studies have focused on L2 or ESL students (Braine, 2001 ${ }^{[12]}$; DiGiovanni \& Nagaswami, 2001 ${ }^{[13]}$ ). And most of the researches have been centered on the advantages of efeedback, the effect of peer comments on revision, or the comparison between asynchronic and synchronic peer review mode. 


\section{REVIEW OF E-FEEDBACK}

\section{A. Advantages of E-feedback}

One benefit of this e-feedback system is a reduction in paperwork problems like losing or forgetting papers (Palmquist, 1993 ${ }^{[14]}$; Sullivan, Brown, \& Nielson, 1998 ${ }^{15]}$ ). As a digital written form, student commentary can be transmitted electronically without the logistical complications of copying and distributing papers (Tannacito $\&$ Tuzi, 2002 $2^{[16]}$. Such feedback can be in the form of synchronous chat system interactions, asynchronous email, and bulletin-board postings. Thus, students will no longer lose or forget their work. Teachers will not need to carry, or possibly lose, bundles of papers.

Another advantage of online peer feedback is the possibility of a less threatening environment that encourages greater and more equal member participation than face-toface conferencing. ESL students, in particular, seem to benefit from such an environment. For example, Di Giovanni and Nagaswami $(2001)^{[13]}$ observed that students in precollege ESL writing classes participated in online peer feedback comfortably and remained on task. Similarly, Sullivan and Pratt (1996) ${ }^{[17]}$ found that computer-assisted ESL peer discussion had $100 \%$ participation compared to only $50 \%$ participation in the face-to-face class. Explaining how online interactions encouraged participation, Jones et al. (2006) ${ }^{[18]}$ suggested the electronic environment freed ESL students from the embarrassment to speak English with peers who shared the same first language versus what they experienced in face-to-face encounters. Liu and Sadler $(2003)^{[19]}$ also noted that the online environment facilitated participation of ESL students whose cultures placed a strong value on listening and silence in traditional classrooms. Japanese students, for instance, are socialized in an educational system where student-initiated classroom interaction is discouraged. The non-threatening environment of this type of peer feedback seems to be related to the anonymity that cyberspace offers. Without worrying about how handwriting in the traditional paper-based mode might reveal the reviewer's identity, some students said that using pseudonyms in cyberspace allowed them to make honest comments and try out different roles or develop a "writerly persona" (Strenski et al., 2005, p. 195) ${ }^{[20]}$. Highapprehensive student writers in Mabrito's (1991) ${ }^{[21]}$ study also experienced more freedom to participate anonymously in email peer feedback and "to engage in a collaborative venture that they might otherwise have avoided in a face-toface setting" (p. 529).

In addition, this new type of feedback changes the role of the teacher and the ability to monitor conversations because the environment that teachers and students typically perform in when responding is being replaced with a new forum, an electronic one. DiGiovanni and Nagaswami (2001) indicated that e-feedback provided a better means of monitoring conversations. Without the Internet, it will become overly complicated to publish the assignments and reviews in paper for every student in the class, to control deadlines, group formation and manage the whole process. Since online peer feedback was available to the instructors, they could monitor the conversations and provide guidance to writers who needed it. Knowing that the teachers could monitor their conversations also encouraged the students to stay on task. DiGiovanni and Nagaswami (2001) ${ }^{[13]}$ also identified that "computer conversations are a form of hybrid communication that allows students to respond spontaneously, yet offers them the opportunity to reflect on their ideas, rehearse their responses, and respond at their own pace" (p. 269). These options are not typically evident in traditional oral feedback or in traditional written feedback.

Finally, from the physical and psychological perspective, Jordan-Henley and Maids (1995) ${ }^{[22]}$ suggests that when focusing on writing in cyberspace, students "are released from much of the responsibility that a face-to-face encounter sometimes forces on them. They are not affected, for instance, by students with bad breath, or by students who make them uncomfortable in some vague way, or by students who are angry with a teacher" (p. 212).

In short, research in L2 classrooms indicates that networked computers do indeed enhance opportunities and motivation for authentic interaction and meaningful negotiation (Kern, 2003) ${ }^{[2]}$; reduce anxiety and produce more talk (Fanderclai, 1995) ${ }^{[23]}$; and improve linguistic proficiency and increase self-confidence (Beauvois \& Eledge, $1996)^{[24]}$. As a potentially powerful tool for collaborative writing, Moreira \& Da Silva (2003) ${ }^{[25]}$ summarizes the advantages of the method of on-line peer review:

1) It is less demanding on staff;

2) Students would learn to master the following skills while judging the work of fellow students among student groups:

- The ability to present their work to peers.

- The social skills for making criticism of their peer' work in a respectful and polite way.

- The social skill for accepting criticism to one's own work from peers in a positive and constructive way.

Those are skills the students will use throughout their lives. (pp. 51-52)

\section{B. Effects of Peer Comments on Revision}

The differences between traditional and electronic environments are reflected in the different types of peer comments they generate. For instance, Jones et al. (2006) ${ }^{[18]}$ compared peer interactions online with those in the traditional face-to-face mode and found the former generated more feedback on global concerns of content and the writing process whereas the latter focused more on local textual issues of grammar, style, and word choice. However, other researchers found that peer e-feedback using Microsoft Word or other special programs designed for responding to writing actually generated more concrete and revision-oriented comments than traditional oral or paper-based feedback ( Liu $\&$ Sadler, 2003 ${ }^{[19]}$. Freed from the face-to-face encounters of the traditional classroom, some online group discussions developed into critical and effective negotiations (DiGiovanni \& Nagaswami, 2001 ${ }^{[13]}$; Sullivan \& Pratt, 
$\left.1996^{[17]}\right)$. By comparing students' initial and revised drafts after e-feedback and oral feedback, Tuzi $(2004)^{[26]}$ found L2 students made more macro-level revisions following efeedback, adding new information and revising structures at clause, sentence, and paragraph levels. In addition, Matsumura and Hann (2004) ${ }^{[27]}$ reported that ESL students who did not post their own drafts online because of high computer anxiety also benefited from reading other classmates' drafts and related comments.

\section{Comparison of Asynchronic and Synchronic Peer Review Mode}

In his comparison of feedback sessions using an asynchronous mode (email) and a synchronous one (chat), Honeycutt $(2001)^{[28]}$ found that "asynchronous media tend to produce more directive comments about potential revision strategies, whereas synchronous conferencing supports informative and elicited comments indicating a greater amount of personal and collaborative involvement between participants"' (p. 54). And synchronous networking could be unnatural when it requires "a roomful of people to type to each other rather than hold a discussion" (Susser, 1993, p. $71)^{[29]}$. Researchers have found synchronous chats sometimes disjointed, scattered, confusing, and disruptive (Braine, 2001 ${ }^{[12]}$; Honeycutt, 2001 ${ }^{[28]}$; Liu \& Sadler, 2003 ${ }^{[19]}$ ). In comparison, asynchronous email feedback has been found to have less time pressure (Tannacito \& Tuzi, 2002) ${ }^{[30]}$, and to be more serious (Honeycutt, 2001) [18] $^{[18}$ and more effective as students learn to adapt their verbal behaviors over time to reach similar interpersonal levels observed in synchronous chats (Walther, 1996) ${ }^{[31]}$.

Unfortunately, while much of the research above is mainly introduced from the foreign countries, few is conducted in China. Up to now, only two empirical researches concerned with e-feedback has been found in the Chinese Journal Full-text Database (CJFD) - Chinese National Knowledge Infrastructure (CNKI). One is Jiang's $(2005)^{[32]}$ research on the 119 English majors in one university in Chongqing. The study tried to explore the effect of online peer review on the improvement of students' writing. The result showed that online peer review could improve students' writing motivation and initiative, release anxiety and psychological pressure and was helpful for the revision. The other is the research by Liu and Yang $(2008)^{[33]}$ who compared the effect of online peer review and traditional teacher feedback. The results showed that a significant difference exists between scores of the experimental class (students conducting online peer review) and those of the traditional class (students receiving teacher feedback), which proved that online interaction and web information were helpful to students. However, the two experiments have not analyzed the students' revision works in detail. Hence, the advantages are not fully performed in these two experiments.

\section{CONCLUSION}

University curricula today show an increasing emphasis on the learning of complex skills such as writing, inquiring and problem solving. This means that students produce more complex work, such as reports, articles and project presentations. As the available teaching time in most institutions does not increase, teachers are urged to find new ways to provide feedback. A practical benefit of implementing peer review is that the feedback comes in much larger quantities than the teacher could ever provide alone, and becomes available much sooner. A more pedagogical reason for implementing peer feedback is that it resembles professional practice. Providing and receiving feedback from work colleagues is a common learning activity in many professional practices (Billet, 2002 ${ }^{[35]}$; Eraut, $2004)^{[36]}$. As such, the concept of peer feedback fits in well with recent developments in university teaching, such as collaborative learning and writing, and real-life task performance (Van Weert \& Pilot, 2003 ${ }^{[37]}$ ). With the rapid development of electronic equipment, the students have more and more means to promote their studying. E-feedback, as a useful revising tool, if used properly, it can greatly improve the students' English learning effect. But how to make full use of the electronic equipment to help the EFL studying without being distracted by the other amusement program is a problem left for all us teachers to think it over.

\section{REFERENCES}

[1] Huot, B. (2002). Toward a new discourse of assessment for the college writing classroom. College English, 65, 163-180.

[2] Kern, V.M., Saraiva, L.M., \& dos Santos Pacheco, R.C. (2003). Peer review in education: Promoting collaboration, written expression, critical thinking, and professional responsibility. Education and Information Technologies, 8(1), 37-46.

[3] Rollinson, P. (2005). Using peer feedback in the ESL writing class. ELT Journal, 59, 23-30.

[4] DeGuerrero, M., \& Villamil, O. (1994). Social cognitive dimensions of interaction in L2 peer revision. The Modern Language Journal, 78(4), 484-496.

[5] Villamil, O.S., \& DeGuerrero, M.C. (1996). Peer revision in the L2 classroom: Social-cognitive activities, mediating strategies, and aspects of social behavior. Journal of Second Language Writing, 5(1), 51-75.

[6] Tsui, A.B., \& Ng, M. (2000). Do Secondary L2 Writers Benefit from Peer Comments? Journal of Second language Writing, 9(2), 141-170.

[7] Min, H.T. (2005). Training students to become successful peer reviews. System, 33, 293-308.

[8] Mittan, R. (1989). The peer review process: Harnessing students' communicative power. In Johnson, D.M., \& Roen, D.H. (Eds.), Richness in Writing: Empowering ESL students (pp. 207-219). New York: Longman.

[9] Byrd, D.R. (2004). Practical tips for implementing peer editing tasks in the foreign language classroom. Foreign Language Annuals, 36(3), 434-441.

[10] Lockhart, C., \& Ng, P. (1995). Analyzing talk in peer response groups: Stances, functions, and content. Language Learning, 47(1), 143.

[11] Mangelsdorf, K. (1989). Parallels between speaking and writing in second language acquisition. In Johnson, D., \& Roen, D. (Eds.), Richness in Writing: Empowering ESL Students (pp. 134-135). White Plains, NY: Longman.

[12] Braine, G. (2001). A study of English as a foreign language (EFL) writers on a local-area network (LAN) and in traditional classes. Computers and Composition, 18, 275-292.

[13] DiGiovanni, E. \& Nagaswami, G. (2001). Online peer review: An alternative to face-to-face? ELT Journal 53(3), 263-272. 
[14] Palmquist, M. (1993). Network-supported interaction in two writing classrooms. Computers and Composition 10(4), 25-57.

[15] Sullivan, D., Brown, C.E., \& Nielson, N.L. (1998). Computermediated peer review of student papers. Journal of Education for Business, 74(2), 117-121.

[16] Tannacito, T., \& Tuzi, F. (2002). A comparison of e-response: Two experiences; one conclusion. Kairos: A Journal of Rhetoric, Technology, and Pedagogy, 7(3), 1-21.

[17] Sullivan, N., \& Pratt, E. (1996). A comparative study of two ESL writing environments: A computer-assisted classroom and a traditional oral classroom. System, 29, 491-501.

[18] Jones, R.H., Garralda, A.L., David C.S., \& Lock, G. (2006). Interactional dynamics in online and face-to-face peer-tutoring sessions for second language writers. Journal of Second Language Writing, 15, 1-23.

[19] Liu, J., \& Sadler, R.W. (2003). The effect and affect of peer review in electronic versus traditional modes on L2 writing. Journal of English for Academic Purposes, 2, 193-227.

[20] Strenski, E., Feagin, C.O., \& Singer, J.A. (2005). Email small group peer review revisited. Computers and Composition, 22, 191-208.

[21] Mabrito, M. (1991). Electronic mail as a vehicle for peer response: Conversations of high- and low-apprehensive writers. Written Communication, 8, 509-532.

[22] Jordan-Henley, J., \& Maid, B.M. (1995). Tutoring in cyberspace: Student impact and college/university collaboration. Computers and Composition, 12, 211-218.

[23] Fanderclai, T.L. (1995). MUDs in education: New environment, new pedagogies. Computer-Mediated Communication Magazine, 2, 8-10.

[24] Beauvois, M.H., \& Eledge, J. (1996). Personality types and megabytes: Student attitudes toward computer mediated communication (CMC) in the language classroom. CALICO Journal, $13,27-45$.

[25] Moreira, D.D.A., \& Da Silva, E.Q. (2003). A method to increase student interaction using student groups and peer review over the internet. Education and Information Technologies, 8(1), 47-54.

[26] Tuzi, F. (2004). The impact of e-feedback on the revisions of L2 writers in an academic writing course. Computers and Composition, 21, 217-235.

[27] Matsumura, S., \& Hann, G. (2004). Computer anxiety and students' preferred feedback methods in EFL Writing. Modern Language Journal, 88, 403-415.

[28] Honeycutt, L. (2001). Comparing e-mail and synchronous conferencing in online peer response. Written Communication, 18, 26-60.

[29] Susser, B. (1993). Networks and projectwork: Alternative pedagogies for writing with computers. Computers and Composition, 10, 63-89.

[30] Tannacito, T., \& Tuzi, F. (2002). A comparison of e-response: Two experiences; one conclusion. Kairos: A Journal of Rhetoric, Technology, and Pedagogy, 7(3), 1-21.

[31] Walther, J.B. (1996). Computer-mediated communication: Impersonal, interpersonal, and hyperpersonal interaction. Communication Research, 23, 3-43.

[32] Jiang, Y.H. (2005). The role of online peer review in learners' writing ability development. Foreign Language Teaching and Research (bimonthly), 37(3), 226-231.

[33] Liu, X.L., \& Yang, G.Y. (2008). A study on web-based peer revision in college-English writing. $F L C, 5(2), 54-58$.

[34] Liu, J., \& Hansen, J. (2002). Peer Response in Second Language Writing Classrooms. Ann Arbor: University of Michigan Press.

[35] Billet, S. (2002). Critiquing workplace learning discourses: Participation and continuity at work. Studies in the Education of Adults, 34(1), 56-68.

[36] Eraut, M. (2004). Informal learning in the workplace. Studies in Continuing Education, 26(2), 247-273.

[37] Van Weert, T.J., \& Pilot, A. (2003). Task-based team learning with ICT: Design and development of new learning. Education and Information Technologies, 8(2), 195-214. 